Available online at www.eccomasproceedia.org

Eccomas Proceedia UNCECOMP (2021) 302-312

ECCOMAS

Proceedia
UNCECOMP 2021

$4^{\text {th }}$ ECCOMAS Thematic Conference on Uncertainty Quantification in Computational Sciences and Engineering M. Papadrakakis, V. Papadopoulos, G. Stefanou (eds.) Streamed from Athens, Greece, 28 -30 June 2021

\title{
AN EXPERIMENTAL STUDY OF VARIABILITY IN DAMPING, FREQUENCY RESPONSE AND MODAL DATA
}

\author{
Asish Kumar Panda ${ }^{1}$, Subodh V. Modak ${ }^{2}$ \\ ${ }^{1}$ Indian Institute of Technology Delhi \\ Hauz Khas, New Delhi 110016 \\ e-mail: Asish.Kumar.Panda@mech.iitd.ac.in \\ ${ }^{2}$ Indian Institute of Technology Delhi \\ Hauz Khas, New Delhi 110016 \\ e-mail.svmodak@mech.iitd.ac.in
}

\begin{abstract}
Accurate modelling of the damping in structures, along with the mass and stiffness properties, is important for an accurate prediction of the dynamic response. Also important is modeling of the variability in damping, along with the variability the mass and stiffness properties, from sample to sample if the variability of the dynamic response is to be accurately predicted. The present work is a part of the ongoing efforts in this direction. The objective of this paper is twofold. The first is to study the variability of the damping factors of various modes of the test structure over its several samples. The second objective is to study the variability when the test structures are made up of different materials. An experimental study is conducted on beam samples of three different materials, Mild steel, Aluminum and Acrylic. Variability in frequency response functions (FRFs), modal data including variability of damping factors is quantified. The study offers some important insights into importance of modeling of damping uncertainty for making accurate structural dynamic predictions.
\end{abstract}

Keywords: Frequency Response Functions, Variability, Damping Factors, Uncertainty, Experimental Study

ISSN:2623-3339 (C) 2021 The Authors. Published by Eccomas Proceedia.

Peer-review under responsibility of the organizing committee of UNCECOMP 2021.

doi: $10.7712 / 120221.8039 .18992$ 


\section{INTRODUCTION}

Finite Element (FE) Models are widely used for analysis of engineering structures. A finite element model that accurately represents the dynamic behavior of a system is very useful for structural dynamic design and analysis, damage detection, structural health monitoring and vibration control [1]. Despite the high sophistication of FE modeling, prediction of dynamic characteristics using FE models often shows considerable discrepancies with respect to the experimental measurements. These discrepancies may arise due to modeling inaccuracies associated with material properties, boundary conditions, joints, damping and due to the idealization and simplifications made in the modeling [1,2]. Measurement noise may also contribute to these discrepancies. The conventional approach to FE model updating is typically deterministic in nature [3-6], which means that the experimental data is obtained from a single test piece and therefore the measured data does not have any variability. It is observed that the engineering structures in practice, all conforming to the same nominal design have a variability associated with them. In view of this, the deterministic FE model cannot accurately represent the dynamics of a population of nominally identical structures. The variability in the measured dynamic characteristics occurs due to inherent variation in the material properties, geometry and manufacturing from specimen to specimen. Variability may also arise due to measurement noise $[7,8]$, environmental effect, damage [9], disassembly and reassembly of the same structure [10] and material degradation over a period of time. It is therefore desired that the FE model is also able to predict the variability of the dynamic characteristics across the samples. This has led to development of stochastic approaches to model updating where both the deterministic as well stochastic uncertainties in the model are identified. Most current methods of Stochastic FE model updating identify uncertainties in parameters associated with the mass and stiffness matrices $[8,11,12]$. This allows predicting variability of natural frequencies and mode shapes.

However, the question arises about the extent of the variability of dynamic response over the samples of the test structure. The variability of the dynamic response depends on the variability of the damping loss factors. In the light of this, one of the objectives of this paper is to study the extent of variability of damping factor that occurs across several samples of a given structure. The second objective is to study the variability of dynamic characteristics in samples of materials with different levels of damping. This is carried out for beams of three different materials, Mild steel (MS), Aluminum (Al) and Acrylic.

If the variability of the damping loss factors is significant then this requires modeling variabilities not only in the mass and stiffness matrices but also the damping matrix of FE model so as to enable predicting the variability of the dynamic response.

\section{EXPERIMENTAL STUDY OF VARIABILITY OF DYNAMIC CHARACTERISTICS}

The experiment is carried with three different beam materials, Mild steel, Aluminum and Acrylic. Different samples of beam of each material are tested under free-free condition. FRFs are measured at 16 test points in the transverse direction on each beam sample. An accelerometer is mounted at test point 7 to measure transverse acceleration, while the excitation is given using a modal hammer by hitting at different test points to measure FRFs over a frequency range of $0-1000 \mathrm{~Hz}$. Fig. 1 shows the experimental setup used to measure FRFs. The beam is suspended vertically to ensure that the mass of accelerometer and the stiffness of the string used for suspension does not affect the beam's dynamic characteristics in the transvers direction. 


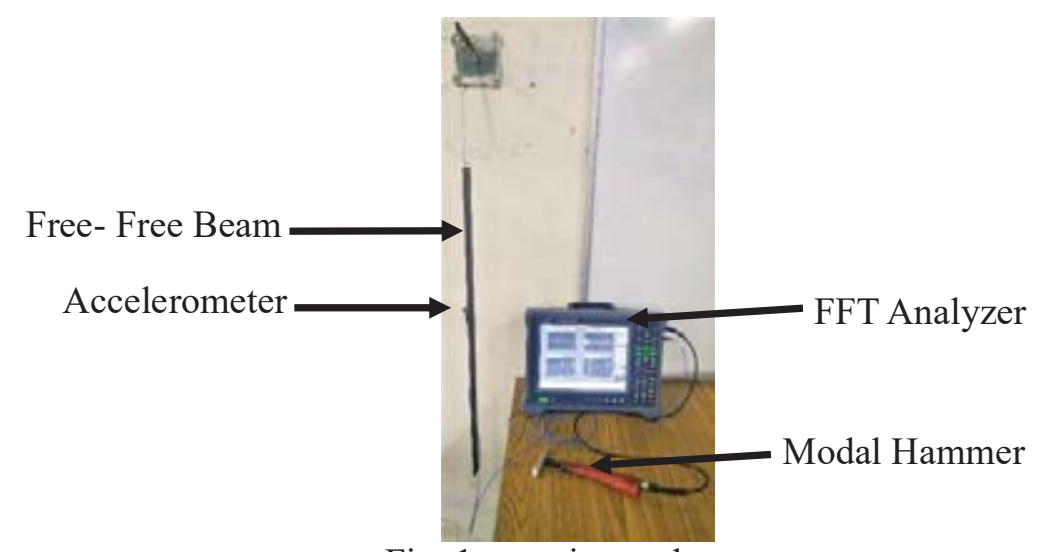

Fig. 1 experimental setup

\subsection{Study on Mild steel beam samples}

The nominal dimensions of the Mild steel beam samples are $(750 \times 31.5 \times 5.3) \mathrm{mm}$ and the mass of the beam is $972 \mathrm{gm}$. Fig. 2 shows overlays of the experimental FRFs of various samples at test point $1,5,7$ and 10 , respectively. It can be seen that the variability in experimental FRFs is increasing as we go up the frequency range. The modal analysis of measured FRFs on the beam samples is carried out. Figs. 3 and 4 show histograms of variability in natural frequencies and loss factors with the fitted normal distributions, respectively, of the MS beam samples. Increasing the number of samples will increase the accuracy of the distributions. Table 1 shows values of mean, standard deviation and coefficient of variation (COV) of natural frequency and loss factor for the first six modes of vibration of the beam samples. It is seen that the standard deviation of natural frequency is increasing with the mode number but the variation in natural frequency as a percentage of the mean value is nearly same for all the modes listed in the table. It is also found that the natural frequencies for different modes vary on an average by $2.6 \%$, while the loss factors vary on an average by $9.81 \%$ over different samples. It is also noted that the COVs of loss factor of higher modes are higher.

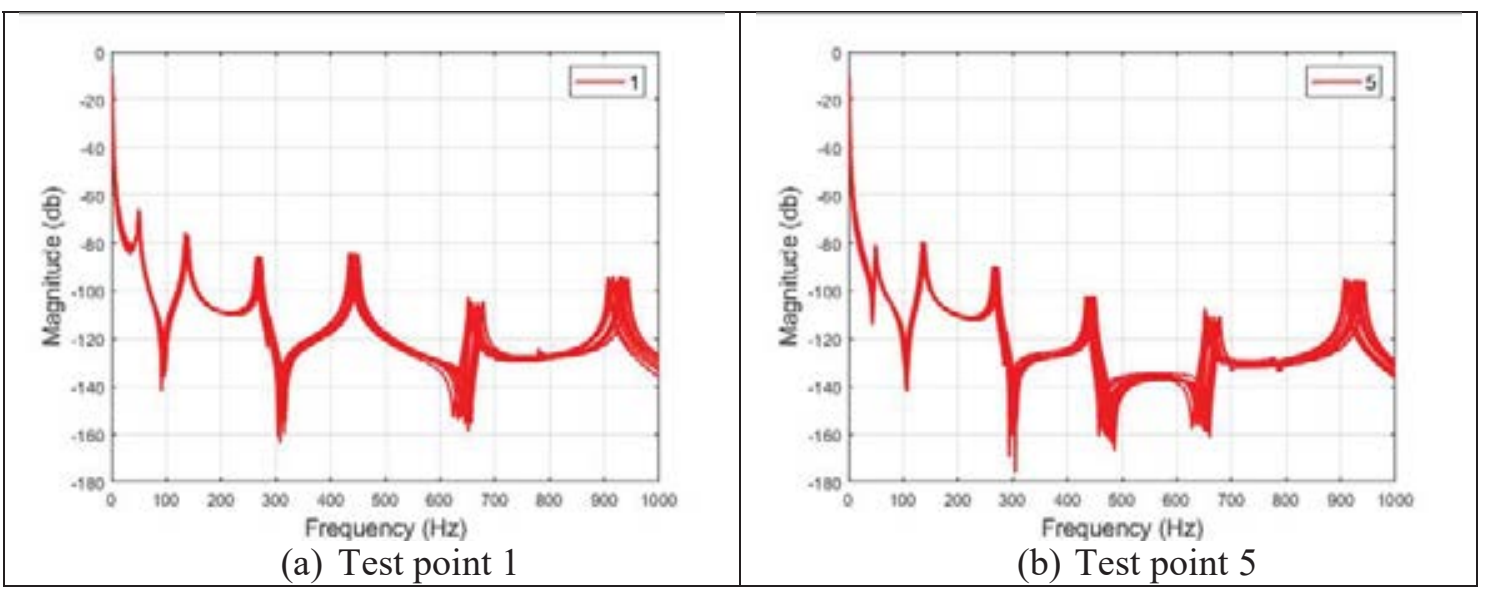




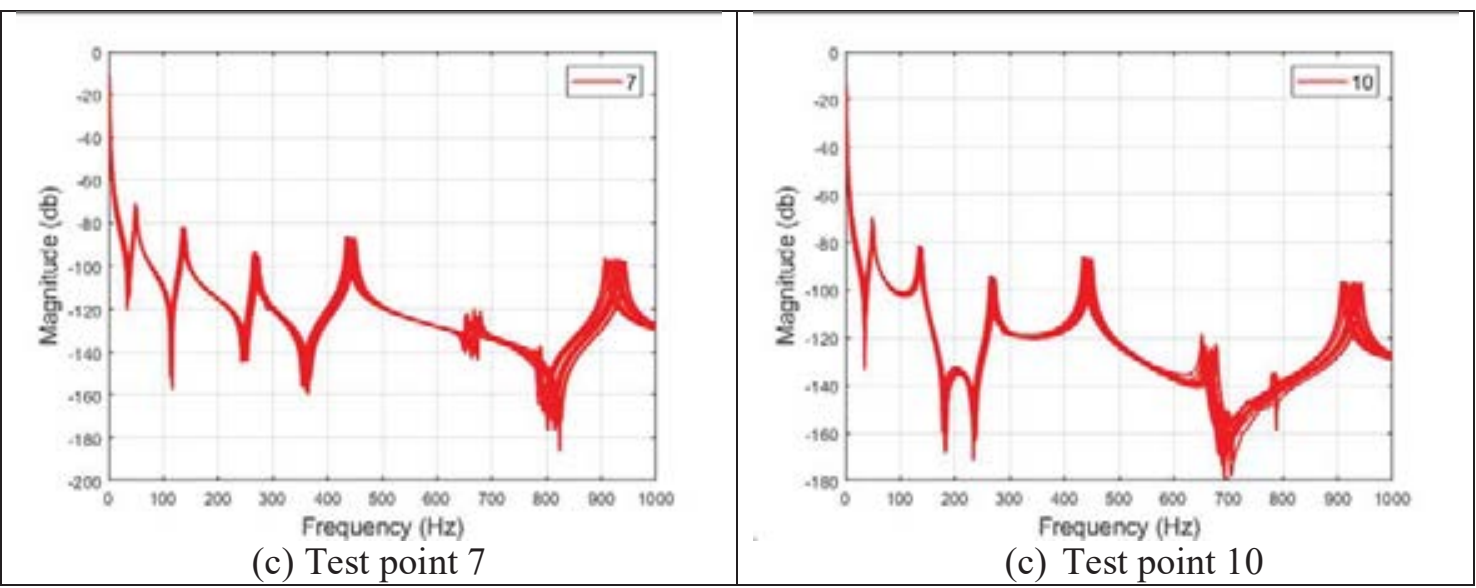

Fig. 2. Overlays of the experimental FRFs measured on various beam samples at test points a) 1 b) 5 c) 7 d) 10

Table 1. Mean, standard deviation and coefficient of variation (COV) of natural frequencies and loss factors

\begin{tabular}{|c|c|c|c|c|c|c|}
\hline \multirow{2}{*}{$\begin{array}{c}\text { Mode } \\
\text { Number }\end{array}$} & \multicolumn{3}{|c|}{ Natural Frequency $(\mathrm{Hz})$} & \multicolumn{3}{c|}{ Loss Factor (\%) } \\
\cline { 2 - 7 } & $\begin{array}{c}\text { Mean } \\
\text { value } \\
\left(f_{\text {mean }}\right)\end{array}$ & $\begin{array}{c}\text { Standard } \\
\text { deviation } \\
\left(f_{\text {std }}\right)\end{array}$ & $\begin{array}{c}\text { Coefficient of } \\
\text { variance } \\
\left(f_{\text {cov }}=\frac{f_{\text {std }}}{f_{\text {mean }}} \times 100\right)\end{array}$ & $\begin{array}{c}\text { Mean } \\
\text { value } \\
\left(L_{\text {mean }}\right)\end{array}$ & $\begin{array}{c}\text { Standard } \\
\text { deviation } \\
\left(L_{\text {std }}\right)\end{array}$ & $\begin{array}{c}\text { Coefficient of } \\
\text { variance } \\
\left(L_{\text {cov }}=\frac{L_{\text {std }}}{L_{\text {mean }}} \times 100\right)\end{array}$ \\
\hline 1 & 49.17 & 1.29 & 2.64 & 0.0421 & 0.0032 & 7.72 \\
\hline 2 & 135.66 & 3.30 & 2.44 & 0.0163 & 0.0007 & 4.14 \\
\hline 3 & 266.60 & 6.37 & 2.39 & 0.0084 & 0.0004 & 4.92 \\
\hline 4 & 438.66 & 10.60 & 2.42 & 0.0055 & 0.0003 & 5.35 \\
\hline 5 & 658.84 & 15.60 & 2.37 & 0.0039 & 0.0008 & 19.33 \\
\hline 6 & 915.77 & 21.89 & 2.39 & 0.0037 & 0.0007 & 17.89 \\
\hline
\end{tabular}
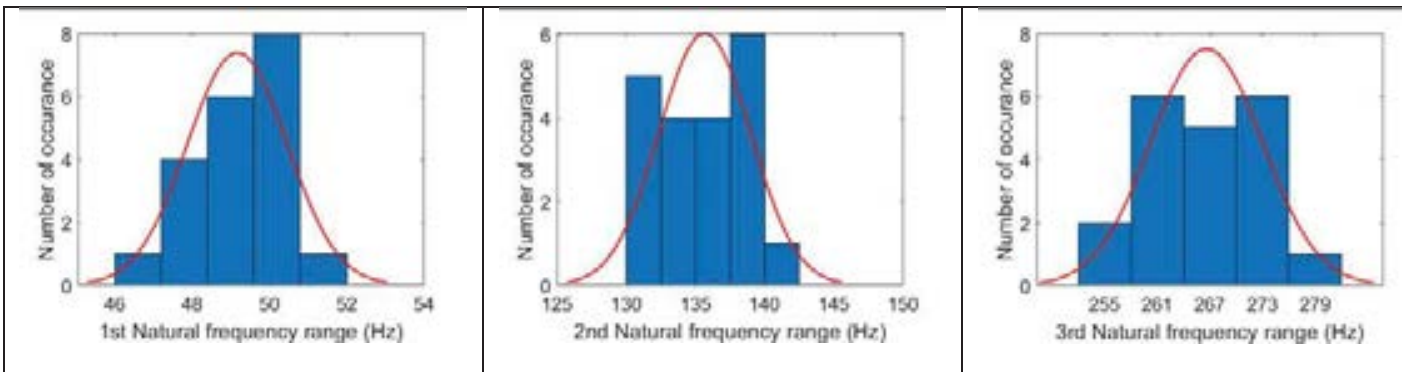


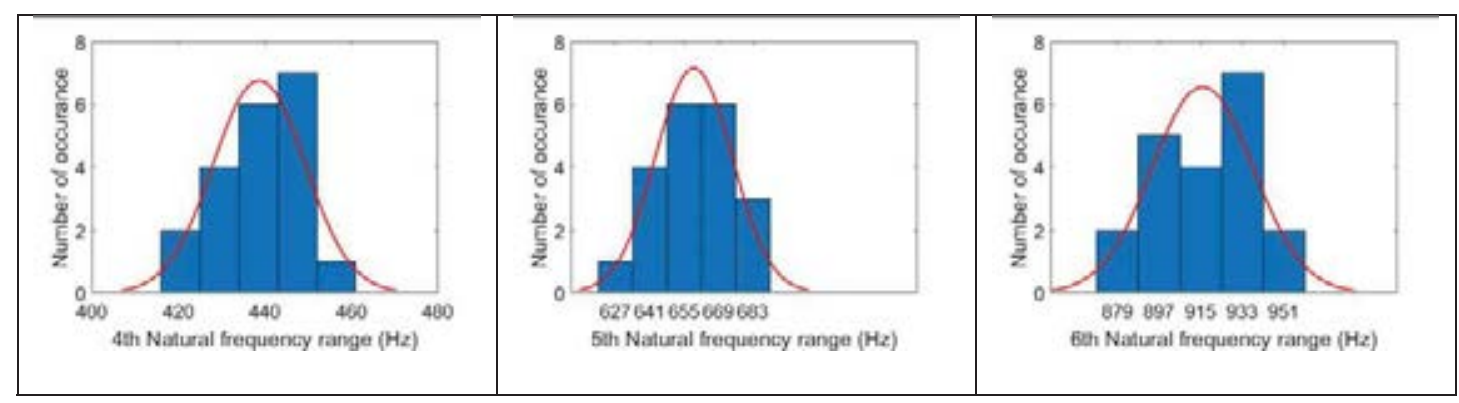

Fig. 3 Histograms of variability in natural frequencies of the MS beam samples

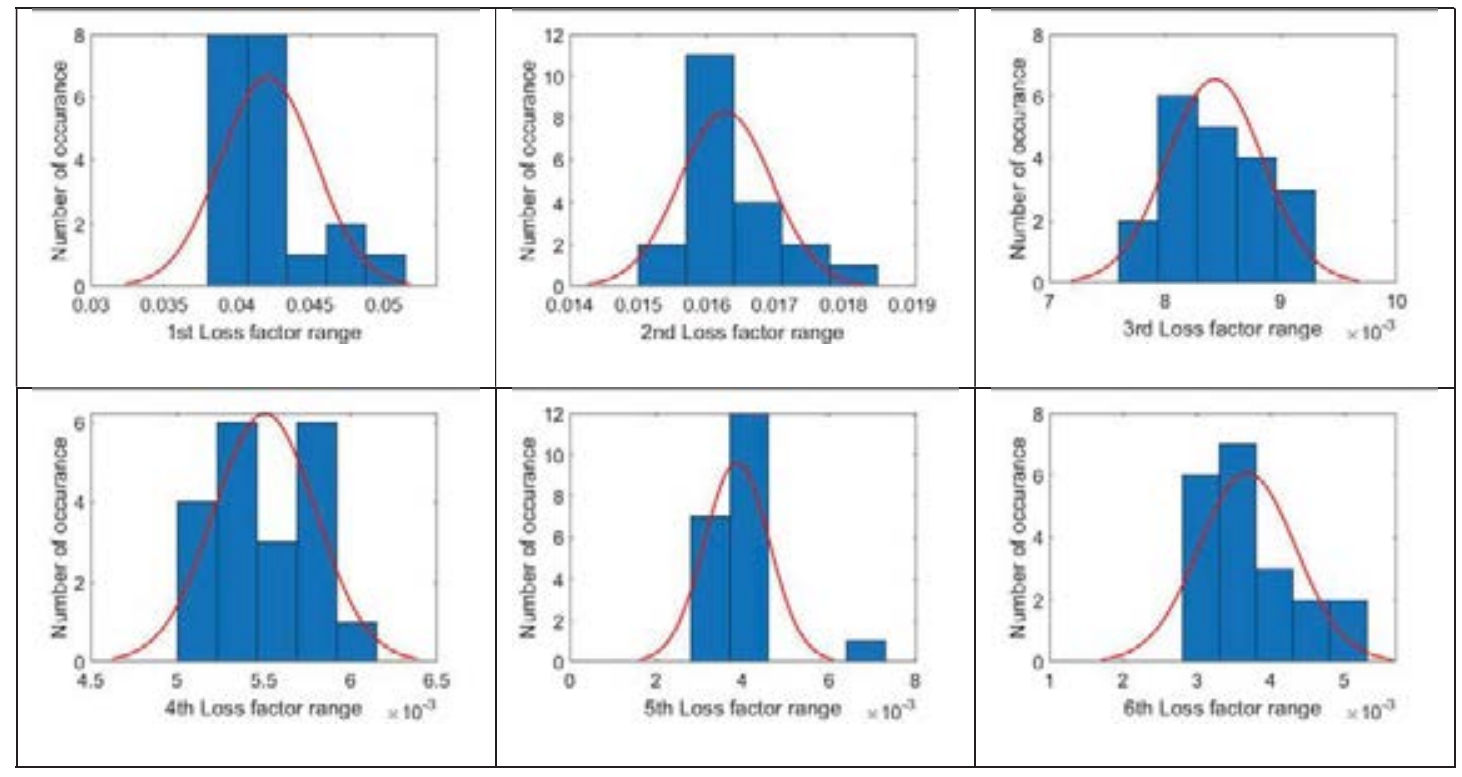

Fig. 4 Histograms of variability in loss factors of the MS beam samples

\subsection{Study on Aluminum beam samples}

In this section, 20 different Aluminum beam samples with nominal dimensions $(750 \times 29.6 \times 5.8) \mathrm{mm}$ are used for the study. The nominal mass of the beam samples is $467.8 \mathrm{gm}$. Fig. 5 shows overlays of the experimental FRFs of various samples at test points 2, 5, 7 and 11, respectively. It is seen that, like MS beam, the variability in experimental FRFs increases as we go up the frequency range. The modal analysis of measure FRFs on the beam samples is carried out. Figs. 6 and 7 show histograms of variability in natural frequencies and loss factors with the fitted normal distributions, respectively, of the Al beam samples. Table 2 shows values of mean, standard deviation and coefficient of variation (COV) of natural frequency and loss factor for the first six modes of vibration of the beam samples. It is seen that, like MS beam the standard deviation of natural frequency is increasing with the mode number but the variation in natural frequency as a percentage of the mean value is nearly same for all the modes listed in the table. It is also found that the natural frequencies for different modes vary on an average by $1.5 \%$, while the loss factors vary on an average by $14.32 \%$ over different samples. It is also noted that the COVs of loss factor of higher modes are higher. 


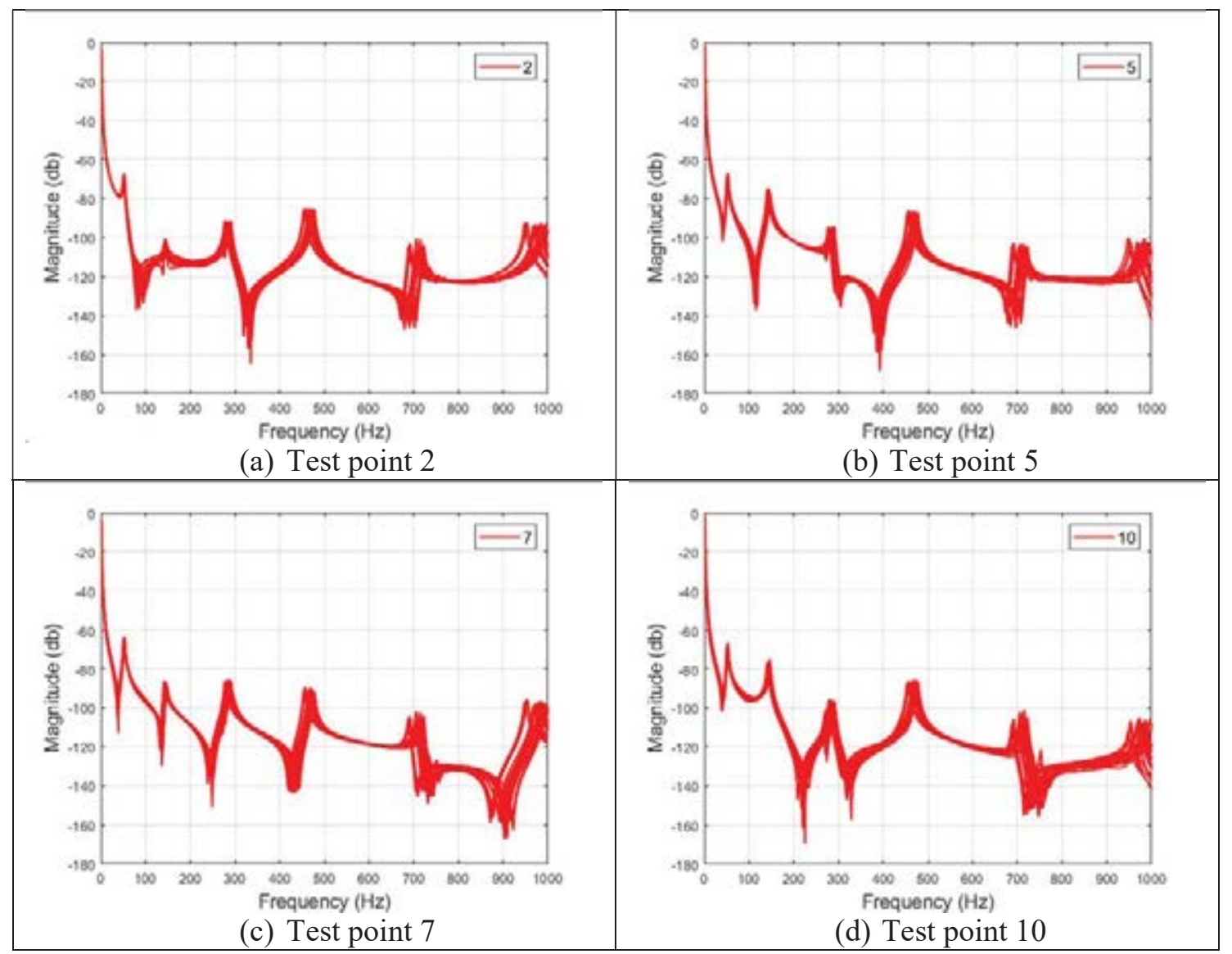

Fig. 5 Overlays of the experimental FRFs measured on various $\mathrm{Al}$ beam samples at test points a) 2 b) 5 c) 7 d) 10

Table 2. Mean, standard deviation and coefficient of variation (COV) of natural frequencies and loss factors (Al beams)

\begin{tabular}{|c|c|c|c|c|c|c|}
\hline \multirow{2}{*}{$\begin{array}{c}\text { Mode } \\
\text { Number }\end{array}$} & \multicolumn{3}{|c|}{ Natural Frequency $(\mathrm{Hz})$} & \multicolumn{3}{c|}{ Loss Factor (\%) } \\
\cline { 2 - 7 } & $\begin{array}{c}\text { Mean } \\
\text { value } \\
\left(f_{\text {mean }}\right)\end{array}$ & $\begin{array}{c}\text { Standard } \\
\text { deviation } \\
\left(f_{\text {std }}\right)\end{array}$ & $\begin{array}{c}\text { Coefficient of } \\
\text { variance } \\
\left(f_{\text {cov }}=\frac{f_{\text {std }}}{f_{\text {mean }}} \times 100\right)\end{array}$ & $\begin{array}{c}\text { Mean } \\
\text { value } \\
\left(L_{\text {mean }}\right)\end{array}$ & $\begin{array}{c}\text { Standard } \\
\text { deviation } \\
\left(L_{\text {std }}\right)\end{array}$ & $\begin{array}{c}\text { Coefficient of } \\
\text { variance } \\
\left(L_{\text {cov }}=\frac{L_{\text {std }}}{L_{\text {mean }}} \times 100\right)\end{array}$ \\
\hline 1 & 52.03 & 0.75 & 1.44 & 0.0444 & 0.00236 & 5.31 \\
\hline 2 & 144.38 & 2.13 & 1.47 & 0.0026 & 0.00265 & 9.82 \\
\hline 3 & 285.80 & 4.49 & 1.57 & 0.0207 & 0.00570 & 27.56 \\
\hline 4 & 467.21 & 7.14 & 1.53 & 0.0090 & 0.0001 & 11.21 \\
\hline 5 & 707.38 & 10.48 & 1.48 & 0.0058 & 0.00121 & 20.94 \\
\hline 6 & 975.65 & 14.79 & 1.52 & 0.006 & 0.000664 & 11.05 \\
\hline
\end{tabular}




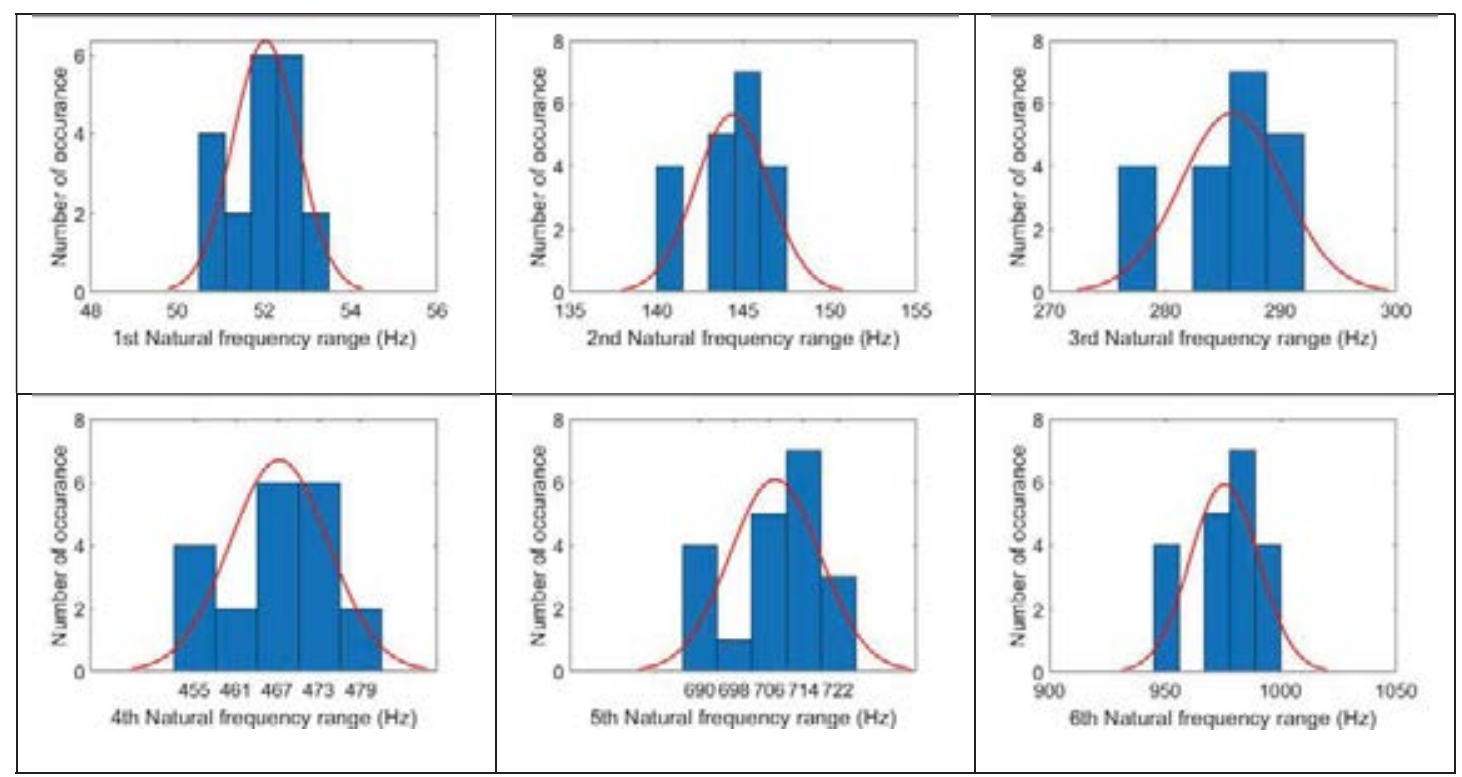

Fig. 6 Histograms of variability in natural frequencies (first six modes) of the Al beam samples

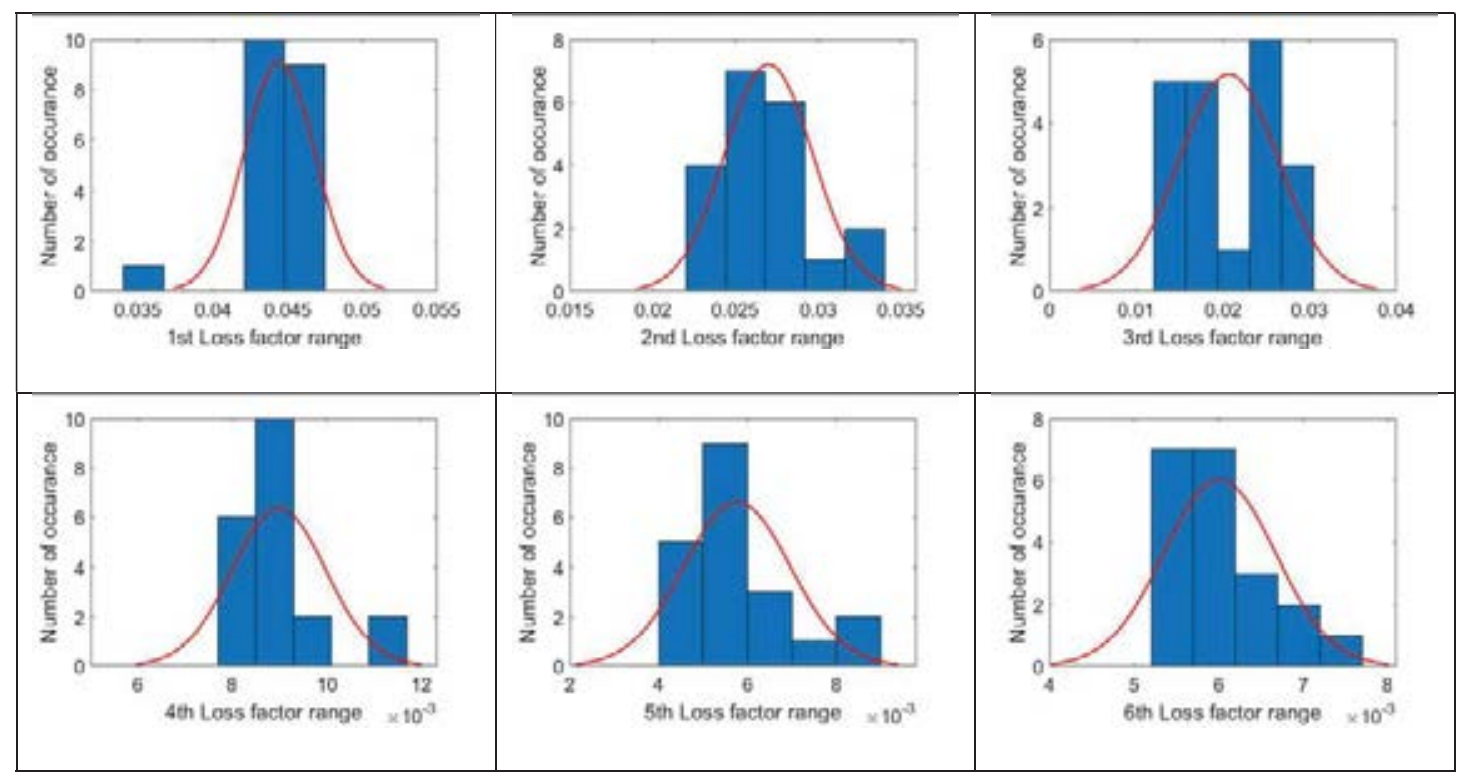

Fig. 7 Histograms of variability in loss factors (first six modes) of the Al beam samples

\subsection{Study on Acrylic beam samples}

In this section, 20 different Acrylic beam samples with nominal dimensions $(750 \times 33.4 \times 3.7)$ $\mathrm{mm}$ are used for the study. The nominal mass of the beam samples is $97 \mathrm{gm}$. Fig. 8 shows overlays of the experimental FRFs of various samples at test points 3, 5, 7 and 11, respectively. It is seen that, like MS and Al beams, the variability in experimental FRFs increases as we go up the frequency range. The modal analysis of measure FRFs on the beam samples is carried 
out. Figs. 9 and 10 show histograms of variability in natural frequencies and loss factors with the fitted normal distributions, respectively, of the Acrylic beam samples. Table 3 shows values of mean, standard deviation and coefficient of variation (COV) of natural frequency and loss factor for the first six modes of vibration of the beam samples. It is seen that, like other two beams, the standard deviation of natural frequency is in-creasing with the mode number but the variation in natural frequency as a percentage of the mean value is nearly same for all the modes listed in the table. It is also found that the natural frequencies for different modes vary on an average by $0.93 \%$, while the loss factors vary on an average by $27.56 \%$ over different samples. It is also noted that the COVs of loss factor of higher modes are higher.

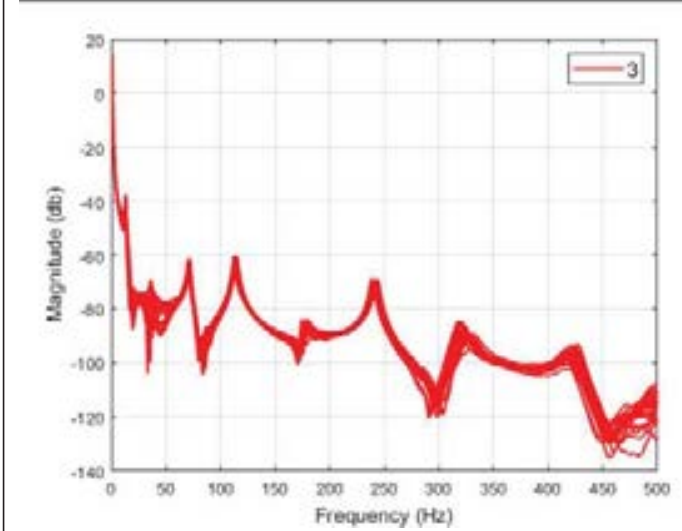

(a) Test point 3

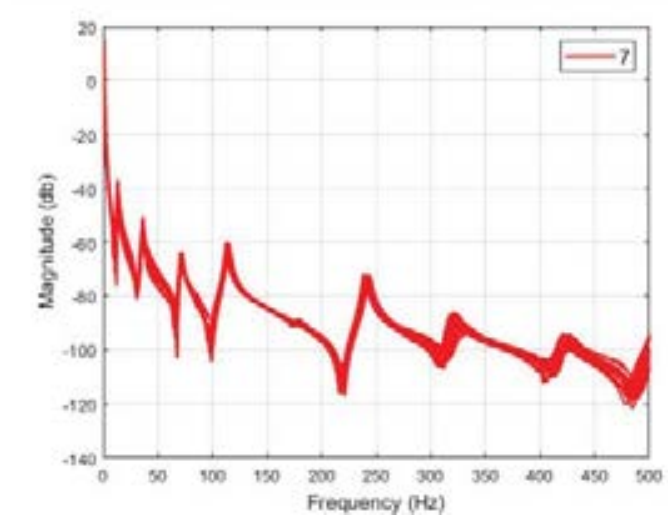

(c) Test point 7

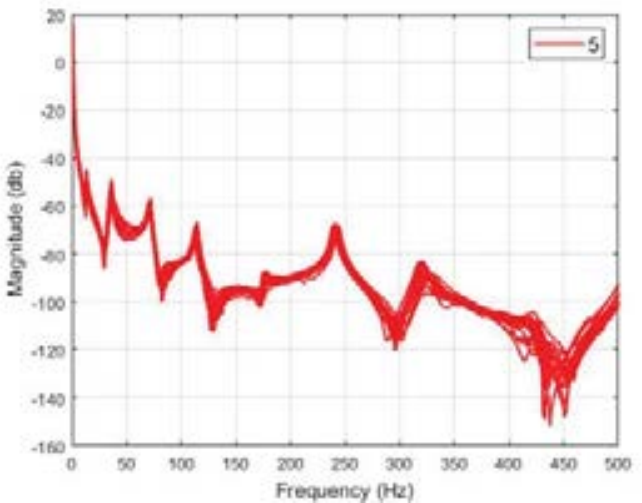

(b) Test point 5

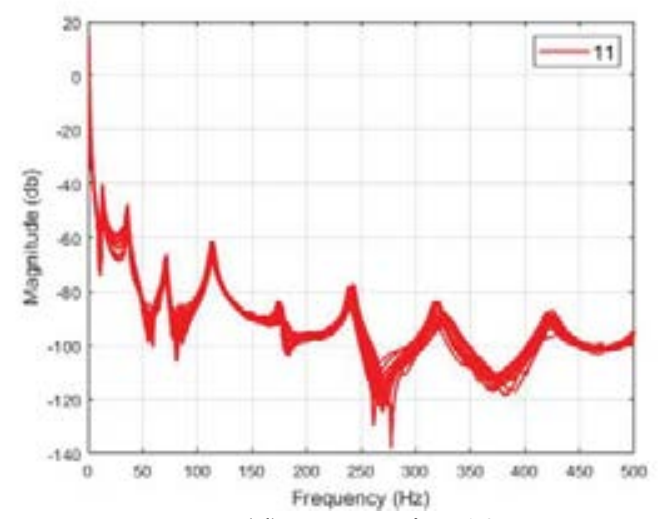

(d) Test point 10

Fig. 8 Overlays of the experimental FRFs measured on various Acrylic beam samples at test points a) 1 b) 5 c) 7 d) 10

Table 3. Mean, standard deviation and coefficient of variation (COV) of natural frequencies and loss factors (Acrylic beams)

\begin{tabular}{|c|c|c|c|c|c|c|}
\hline \multirow{3}{*}{$\begin{array}{c}\text { Mode } \\
\text { Number }\end{array}$} & \multicolumn{3}{|c|}{ Natural Frequency $(\mathrm{Hz})$} & \multicolumn{3}{c|}{ Loss Factor (\%) } \\
\cline { 2 - 7 } & $\begin{array}{c}\text { Mean } \\
\text { value } \\
\left(f_{\text {mean }}\right)\end{array}$ & $\begin{array}{c}\text { Standard } \\
\text { deviation } \\
\left(f_{\text {std }}\right)\end{array}$ & $\begin{array}{c}\text { Coefficient of } \\
\text { variance } \\
\left(f_{\text {cov }}=\frac{f_{\text {std }}}{f_{\text {mean }}} \times 100\right)\end{array}$ & $\begin{array}{c}\text { Mean } \\
\text { value } \\
\left(L_{\text {mean }}\right)\end{array}$ & $\begin{array}{c}\text { Standard } \\
\text { deviation } \\
\left(L_{\text {std }}\right)\end{array}$ & $\begin{array}{c}\text { Coefficient of } \\
\text { variance } \\
\left(L_{\text {cov }}=\frac{L_{\text {std }}}{L_{\text {mean }}} \times 100\right)\end{array}$ \\
\hline
\end{tabular}




\begin{tabular}{|l|c|c|c|c|c|c|}
\hline 1 & 13.23 & 0.13 & 1.03 & 0.0980 & 0.01312 & 13.39 \\
\hline 2 & 35.90 & 0.40 & 1.13 & 0.0616 & 0.01744 & 28.32 \\
\hline 3 & 71.41 & 0.66 & 0.93 & 0.0352 & 0.00810 & 23.02 \\
\hline 4 & 113.83 & 1.03 & 0.90 & 0.0303 & 0.00799 & 26.38 \\
\hline 5 & 179.93 & 1.16 & 0.66 & 0.0332 & 0.01455 & 43.84 \\
\hline 6 & 241.80 & 1.53 & 0.63 & 0.0206 & 0.00545 & 26.39 \\
\hline
\end{tabular}

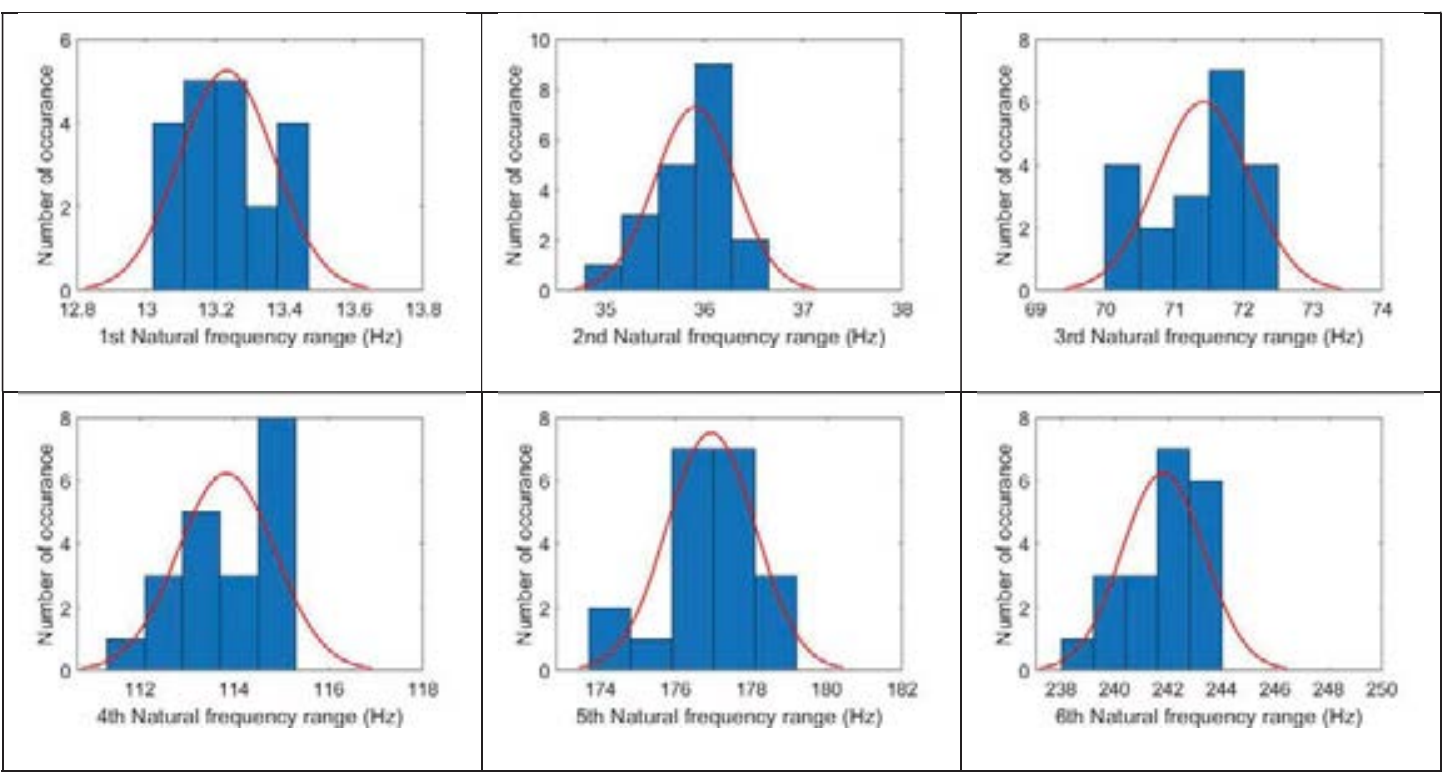

Fig. 9 Histograms of variability in natural frequencies (first six modes) of the Acrylic beam samples

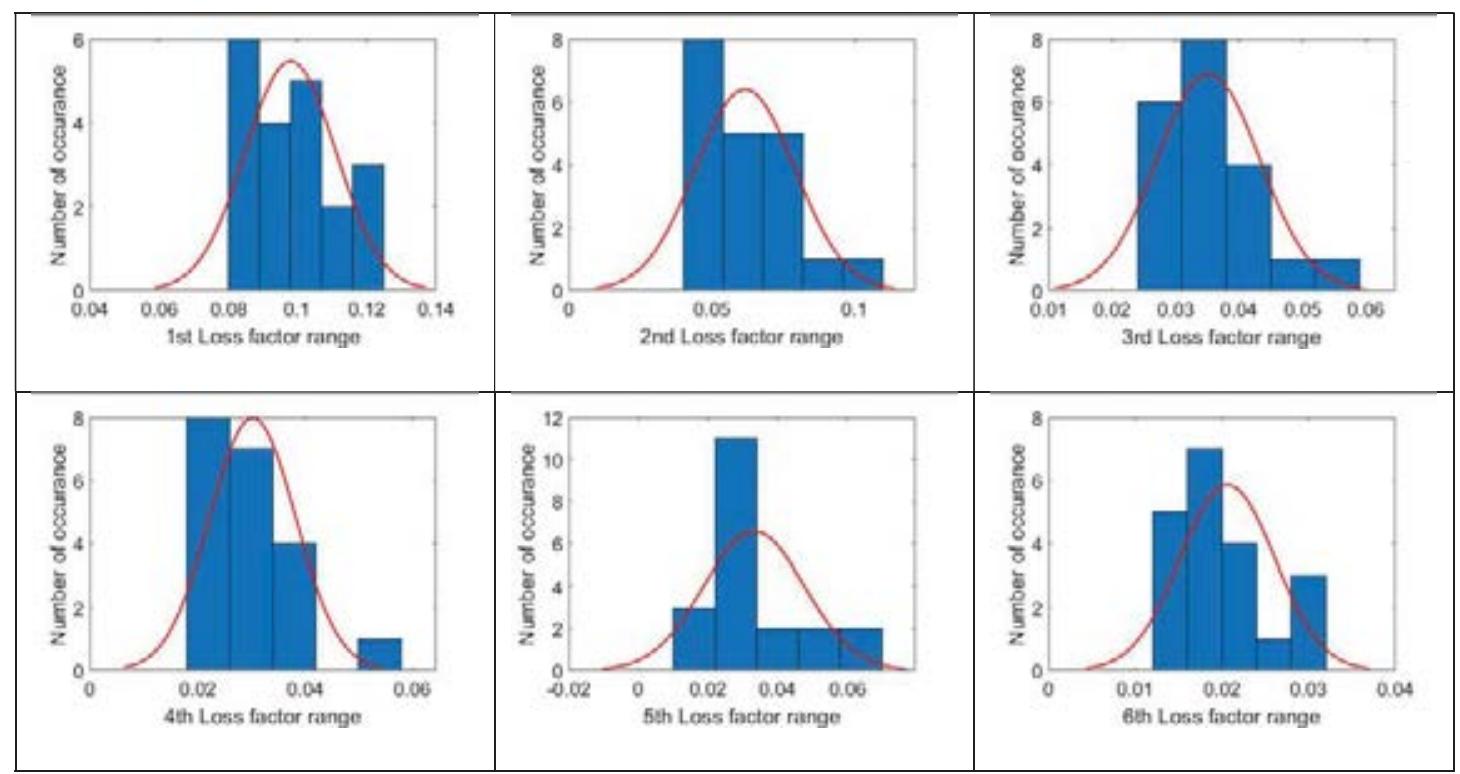


Fig. 10 Histograms of variability in loss factors (first six modes) of the Acrylic beam samples

Table 4. Relative comparison of variability (COV of natural frequencies and loss factors)

\begin{tabular}{|c|c|c|c|c|}
\hline Material Type & \multicolumn{2}{|c|}{ Variability of natural Frequency } & \multicolumn{2}{c|}{ Variability of loss factor } \\
\cline { 2 - 5 } & $\begin{array}{c}\text { Average COV } \\
\text { value of six } \\
\text { modes (\%) }\end{array}$ & $\begin{array}{c}\text { Maximum COV } \\
\text { value of six } \\
\text { modes (\%) }\end{array}$ & $\begin{array}{c}\text { Average COV } \\
\text { value of six } \\
\text { modes (\%) }\end{array}$ & $\begin{array}{c}\text { Maximum COV } \\
\text { value of six } \\
\text { modes (\%) }\end{array}$ \\
\hline MS & 2.6 & 2.64 & 9.81 & 19.33 \\
\hline Al & 1.5 & 1.57 & 14.32 & 27.56 \\
\hline Acrylic & 0.93 & 1.13 & 27.56 & 43.84 \\
\hline
\end{tabular}

\subsection{Comparison of Variability of dynamic characteristic of MS, Al and Acrylic beams}

Table 4 shows a comparison of variabilities of natural frequencies and loss factors of three different beam materials. The table shows average values of COV of natural frequencies and los factors of six modes. It can be seen that average value of COV of natural frequencies decreases, whereas average value of COV loss factors increases, moving from low damping material (MS) to high damping material (Acrylic). Maximum COV values of natural frequencies are closer to the corresponding average values showing that relative variations of COVs of natural frequencies over different mode of same material are small. Maximum COV values of loss factors has a considerable difference as compared to corresponding average values showing that relative variations of COVs of loss factors over different mode of same material varies a lot. These variation are more in higher modes as compared to lower modes.

\section{CONCLUSION}

- The paper presents an experimental study of variability in damping, FRFs and modal data. The investigations are carried out using three experimental beam structures made up of MS, Al and Acrylic. They represent structures with low, medium and high damping.

- From the study, it is observed that different samples of structures show the variability of not only the natural frequencies and FRFs but also the modal damping factors. Thus, there is a need to develop methods for stochastic model updating which can also identify variability damping matrix parameters.

- The study also reveals that the test structures are made up of materials with higher damping show higher variability of damping loss factors and lower variability of natural frequencies as compared to structures made up of material with lower damping.

- It is therefore concluded that modeling of variability in damping is essential since there exists a significant variability of damping loss factors over various samples of the test structures. Modeling of damping variability will help to predict accurately a variability of dynamic response. Hence, methods of stochastic FE model updating need to be developed for identifying variability of damping matrix parameters. 


\section{REFERENCE}

[1] J.E. Mottershead, M.I. Friswell, Model updating in structural dynamics: A survey, J. Sound Vib. (1993). https://doi.org/10.1006/jsvi.1993.1340.

[2] M.I. Friswell, J.E. Mottershead, Finite element model updating in structural dynamics, 1995. https://doi.org/10.1007/978-94-015-8508-8.

[3] F. Asma, A. Bouazzouni, Finite element model updating using FRF measurements, Shock Vib. 12 (2005) 377-388. https://doi.org/10.1155/2005/581634.

[4] M.I. Friswell, D.J. Inman, D.F. Pilkey, Direct updating of damping and stiffness matrices, AIAA J. 36 (1998) 491-494. https://doi.org/10.2514/3.13851.

[5] S. Pradhan, S. V. Modak, Normal response function method for mass and stiffness matrix updating using complex FRFs, Mech. Syst. Signal Process. (2012). https://doi.org/10.1016/j.ymssp.2012.04.019.

[6] S. Pradhan, S.V. Modak, A two-stage approach to updating of mass, stiffness and damping matrices, Int. J. Mech. Sci. 140 (2018) 133-150. https://doi.org/10.1016/J.IJMECSCI.2018.02.033.

[7] J.L. Beck, L.S. Katafygiotis, Updating models and their uncertainities I: Bayesian statistical framework, J. Eng. Mech. 124 (1998). https://doi.org/https://doi.org/10.1061/(ASCE)0733-9399(1998)124:4(455).

[8] X.G. Hua, Y.Q. Ni, Z.Q. Chen, J.M. Ko, An improved perturbation method for stochastic finite element model updating, Int. J. Numer. Methods Eng. 73 (2008) 18451864. https://doi.org/10.1002/nme.2151.

[9] M. Baruch, I.Y. Bar-Itzhack, Optimal weighted orthogonalization of measured modes, AIAA J. 17 (1979) 927-928. https://doi.org/10.2514/3.7529.

[10] M. Imregun, W.J. Visser, D.J. Ewins, Finite element model updating using frequency response function data: I. Theory and initial investigation, Mech. Syst. Signal Process. 9 (1995) 187-202. https://doi.org/10.1006/MSSP.1995.0015.

[11] H.H. Khodaparast, J.E. Mottershead, M.I. Friswell, Perturbation methods for the estimation of parameter variability in stochastic model updating, Mech. Syst. Signal Process. 22 (2008) 1751-1773. https://doi.org/10.1016/J.YMSSP.2008.03.001.

[12] Y. Govers, M. Link, Stochastic model updating-Covariance matrix adjustment from uncertain experimental modal data, Mech. Syst. Signal Process. 24 (2009) 696-706. https://doi.org/10.1016/j.ymssp.2009.10.006. 